\title{
Practice and Research on Art landscape Design Course
}

\author{
Weixiao Zhen \\ Department of Environmental Art Design, Hebei Institute of Fine Art, Shijiazhuang Hebei, 050700, \\ China
}

Keywords: landscape, The curriculum, The teaching way, Creative thinking.

\begin{abstract}
The article with a review of the development of Chinese landscape design discipline education, from the artistic design specialized landscape design teaching curriculum, teaching methods, the cultivation of student's creative thinking three aspects in this paper, the analysis of the landscape design course teaching and research, and through the comparison of similar colleges landscape design professional education practice at home and abroad, discusses the connotation of landscape design professional education. Landscape design course after searching in the domestic many institutions of higher learning in the development and gradually become one of the important basic course of environmental art design professional, and have accumulated some experience in teaching.
\end{abstract}

\section{Background}

With the development of the society, people's income is growing, constantly improve the education level, ecological environment is deteriorated, and people's living, leisure environment quality put forward higher requirements, the organization form of urban space and design requirements into landscape design of the important research subject. The professional landscape design, in China is a great opportunity, and a great challenge. How to develop the education of landscape design in our country, the landscape design course teaching system, training of the new era of landscape designer is an important task in front of us.

Modern design practice in the field of extensity requires the designer with whole, integrated and comprehensive knowledge background, so the landscape design should combine scientific and artistic analysis, the planning and design, management, protection and content included. Accordingly, the landscape design teaching should pay attention to social, ecological and the trinity of art, should not be ignored. Now under the background of education in our country, we should be the subject of landscape design education system to constantly adjust, emphasis on environmental science and the humanities society, absorbing the latest research achievements of other disciplines, reform teaching methods, with an open attitude, eventually to aiming at the sustainable development of the living environment of the holistic landscape design education.

The Landscape Planning And Design Professional Curriculum. Landscape planning and design of specialized course opened earlier rolled. In environmental art design education in China, most of the situation is: all basic course on the freshman and sophomore, junior is a specialized course, on the big four arrange students graduation practice (ground work for later) and graduation thesis and graduation design, basically do not have set up a lot of courses about landscape planning and design. [1] So see, basic course with the time is up, and specialized courses in relatively less time left to students for professional practice time and rarely. Therefore, we recommend a freshman sophomore related basic professional courses, such as the history of landscape architecture, landscape, garden art esthetics, etc., and encourage some additional landscape art design knowledge 
related courses, such as skills classes, vision research lesson, history and theory, social economics, science and technology, etc., so to enrich students' knowledge has a lot of benefits. Domestic landscape design course is mainly for the institutions of higher learning of art and design, city planning, architecture and landscape gardening specialty, and gradually become the environmental art design major in a professional required course. Landscape design course belongs to the liberal arts and science overlapping specialized courses Cheng, complex and strong professional knowledge structure.

Although in landscape design course teaching exploration in recent years, has been a part of the landscape design course teaching methods are discussed in the article, and summarizes a lot of valuable experience, but due to a late start, for this relatively young professional class, there are mainly two aspects: one side, the whole teaching pattern of landscape design inevitably affected by other subjects of traditional teaching mode Single and slightly, difficult to adapt to the social demand for landscape design talents; On the other hand, in each teaching link is also insufficient

We according to Harvard University landscape planning and design professional courses as an example. Like other design professional, course is divided into design class, lectures and seminars, three types of independent study, focus on cultivating the students' design skills, involves many aspects in the field of technology and knowledge, teaching and explore the history of landscape design and theoretical study, carried out a research direction of specialization, students study independently, and write a paper.

The Specific Problems of the Current Domestic Landscape Design Course Teaching. The teaching goals are not clear. Due to the nature of the landscape design course has a multi-disciplinary overlapping, therefore, the domestic various colleges and universities on the basis of resource sharing advantages make full use of campus, the use of the existing related professional in different orientation to landscape design course curriculum. If placed in agronomy in the landscape design course, in which usually add more botanical knowledge; Placed under civil engineering professional landscape design class Cheng, usually join in the curriculum of civil engineering knowledge; And placed in the professional art of landscape design course, are usually more strengthen the knowledge content of art design class, etc.

The education way, combined with its own resources development landscape design in the landscape design education get diversified overall comprehensive development at the same time, also make landscape design course teaching goal becomes fuzzy not clear, and then for the landscape design of the teaching have brought many new problems. As in teaching how to find the equilibrium and balance the related discipline knowledge, avoid the barycenter offset of the course content; In the integration phase close subject knowledge make them supplement each other, how to adopt appropriate teaching methods, etc., will be a breakthrough point of teaching reform research.

The teaching subject simplification. In social practice, the content of the landscape design has a wide range, including residential area landscape design, square landscape design, urban park landscape design, the street landscape design, and other types. However, in the domestic landscape design of the teaching subject, often hard to make a choice, the various types of landscape design task and can only be one or two types of them to make specific training. This relatively single topic selection mode of teaching, to cultivate comprehensive and high quality practical type, landscape design talent, hard to do better meet the social demand for landscape design talent.

The teaching method of simplifying assumptions. At present, the domestic landscape design of the course is usually adopt the teaching methods of theory + design practice, for the landscape design of the relatively strong practical work, this kind of teaching method is too single, for many students real actual content is difficult to grasp. [2] Such as various types of landscape space scale 
and the scale of the landscape space in difficult to accurately; Suffering of landscape space in the sense of reality In order to achieve real; On the landscape design of artificial environment color in photograph reflect with light color changes Difficult to intuitive feelings.

Check method simplification course assessment is one of the effective means of inspection course learning, is an important part in the teaching, but in the current domestic landscape design course examination way, basic limitations in due course design assignments this is relatively single traditional way. Due to the landscape design course with strong practicality and knowledge content of cross particularity, the single way of examination can not comprehensive, integrated, in-depth investigation of students learning the course of real and effective results.

Teaching Methods Should be Diversified. First of all, we should pay attention to the landscape design through discipline. In our country, now open landscape course of colleges and universities and roughly class colleges and universities, the board of agriculture and forestry colleges and universities and building ring art class colleges and universities. Different landscape, landscape design of the curriculum is different: agriculture and forestry colleges students pay attention to the agricultural theory and plant configuration, art expression ability; City landscape direction of gauge, ring arts building students pay attention to the planning of landscape, the lack of plant configuration concept. In addition, basic course too much in a class of agriculture and forestry college, professional class is relatively small and open time late, lead to students' professional ability is weak, the students do the homework blindly copying phenomenon is serious, and so on. Agriculture and forestry colleges and architecture art, city rule class colleges and universities more communication between teachers and students. If conditions permit, you can put these related colleges and universities students team, let them complete the plan of some type, this not only let them learn related knowledge of complementary, but also can cultivate their teamwork spirit, students have the opportunity to make landscape design and architecture, city planning students and professors extensive contacts, cross on knowledge fusion.

Second, firmly grasp the core design course, on the basis of professional skill training, through the optional design classes and a variety of limited choice and of course make students form their own preferences and characteristics in a certain direction. This design in the fierce competition in the international market, it is very meaningful. In addition to customize design courses and a variety of limited choice and of course, the landscape design of the practical courses should be to take the form of lectures, invited to landscape design at home and abroad well-known designers to give a lecture, introduces the latest development of the disciplines and knowledge of related disciplines. Establish contact with foreign schools, teachers, students and the academic exchanges, for students to receive more knowledge, information and skills to provide opportunities, let the students learn professional knowledge in their spare time. Especially in the subject status has not established, lack of full-time faculty, this way is more important.

Thirdly, we should pay attention to the cultivation of students' social practice ability. Let the student summer and winter vacation to garden unit internship, allow them to better understand what society needs talents, how oneself also needs exercise which aspects of the quality and which still need to improve the knowledge of the respect, only in this way, after they go back to school to have a destination to learn better, equipment oneself, can better adapt to society in the future. These knowledge, these requirements are only never can learn in school.

In addition, students should be encouraged to participate in some landscape art design related design competition, this can spur the enthusiasm of the students learning, can promote the academic exchanges, can promote the development of discipline. From the contest theme we can see that people are increasingly concerned by the destruction of the landscape, let the student to participate 
in this competition at the same time, nature will make them a more social sense of responsibility, a sense of responsibility as a landscape architect.

The Cultivation of Creative Thinking Method. In the teaching, I found a lot of students when doing the design, there are a small number of students have their own thoughts, is also very bold idea; Most of the students is to find the relevant data copying, also can't make good use of the data. Its many reasons: the lack of traditional teaching mode, teachers focus on the skills of students learning, and ignored the creation of the originality, the creativity of the students play a constrained; Previous teaching evaluation, the teacher used to traditional standard to evaluate students' work, pay attention to the color of the picture effect, atmosphere rendering, and techniques of painting skills, despise the cultivation of creative thinking, it is difficult to make students get all-round development; In our teaching, we ignore the guides the student to the understanding of their own creative, caused the inert, make students only pay attention to technique and copy, and ignored the essence of art of work.

The essence of design is innovation. If the design left activate the creativity of students the education objective, it cannot be called a real sense of design education. [3] The landscape design of the 21st century education should cultivate what kind of person, this is our each landscape design education workers should ponder question. Why do our students with a solid knowledge of the painting language, but there is little imagination, or almost impossible to imagine? The reason is that our students lack of the most important quality for the artistic creation, creativity. Landscape design should create more embodies the main body of the author's own experience, this requires not only in creation method innovation, more importantly should be multiple perspectives on things, with fresh breath, rather than identical and similar. And our previous teaching is ignored this.

When landscape homework to the student, I often encourage them to go to the evaluation of the scene, the analysis of current field (such as topography, soil, water quality using the crowd), inspiration through personal feeling this site, carries on the artistic design. But I find that most of the students did not do what I have to arrange, but showed a thinking of inertia. They tend to come from some of the other books have been built works, this article directly to copy the work of others, or the works of some of the already made directly copy drawing on your own that piece of ground, don't go to pipe it shape right, site environment similar to or not. This approach not only greatly restricted the cultivation of students creative thinking, and led to the monotony of urban landscape design.

Education activity is a two-way activity, is the process of teachers and students interaction, teachers play the leading role in teaching and students' main body role is equally important, but the traditional education model ignores the students in the main body status in the process of teaching.

First, we should pay more attention to the subject status of students in the teaching process. Landscape design under the traditional education teaching, often on teachers and teaching materials, attaches great importance to the study of teaching materials and teaching methods, but few studies to students the psychological law of learning and learning methods, the teaching process is designed to "teach + accept", in the form of forgetting the student is the master of learning. We should be in the landscape design teaching, guide students in their own unique experience to design, self and emotional integration to work; Guide students to learn to use their own unique perspective to analysis and evaluation, and give full affirmation.

Second, we should to student's creative ability to encourage them. Respect the students and to provide them with harmony, loose and free study atmosphere, to cultivate the students' art of creative thinking is beneficial. [4] Teachers should according to students' individual character difference, improve the occasion, fully excavate the potential of students inner and should be good 
at discovering and encouraging the students' creative spirit and creative ability.

Again, to establish a scientific evaluation system, set up benign teaching feedback mechanism, it is each landscape design education workers are a key part of the teaching work. For a long time, we the deviation exists in the teaching evaluation, is the main reason for the lack of creativity in art teaching. We focus on techniques for evaluating student's creation of the master, and ignore the work of innovative, adopts unified evaluation method, neglected the student's individual differences. Landscape design teaching evaluation should be the teaching activities based on creativity development, skill learning and technique creation at the same time, make the student work in a variety of results, a variety of forms. Lecture courses should be focused on, the key breakthrough, not the pursuit of uniformity of classroom, make students' brains move, do all kinds of art activities and art creation. Only in the teaching innovation and constantly can we change the habit of imitation in the long-term, make each student's individual strengths.

Landscape cognition is with landscape quality of space and its internal elements associated with the overall feeling and understanding. Horizon in the space of material interface is tangible, its internal components between the implication of inner and outer space. [5] A certain elements of landscape quality and the surrounding environment and other factors of the difference between the printed liner relationship: individual factors protrudes from the background "stand out" and "stand out", such as "evergreen among some red" natural combination; "Bring out the best in each other" formed between two elements "should be" to each other, such as "new moon" in Chinese traditional garden space mapping out the foreground and the background, the relationship between as well as the mountain waterfalls "container" and "water" relationship in; The winding path leading to a secluded spot but also reflects the touring experience for a variety of elements of the four-dimensional space-time relationship. The above examples are focusing on the landscape cognition of form and content, while the "want" to "situation in harmony" requires to fully display the inner quality of all kinds of natural scenery.

The "Trinity" of the Teaching Goal. Landscape design course is a practical design course, design process is a from function to form, and from form to function more stages of creative thinking activity, through vision, planning, implementation and production process. Landscape design, therefore, the teaching goal of the course include at least the following three kinds of ability, thinking ability, research ability and design ability to express the three complement each other, be short of one cannot.

Design Thinking Ability. Environmental art professional to develop the students' ability of thinking in design, landscape design as one of the important courses, more emphasis on the design thinking ability of students, to guide the student to carry on the viewing Angle and directional thinking, to find and try to solve the problem of various methods. Design, however, the cultivation of thinking ability is a long and gradual process, can't be through theoretical teaching and the students to master, can only be guided in the process of design practice, this requires teachers to communicate with students, to discuss ways to guide students to think deeply and active innovation.

Research and Analysis Ability. Landscape design is a beautify the problem not only, more is a combination of technology and art courses, therefore, the landscape design course teaching should also pay attention to the combination of art and science and technology knowledge, with emphasis on the design thinking and cultivate students creative rational research and analysis ability. In the teaching, the cultivation of the ability of students to design and analysis can be done through do more scheme evaluation. For design students, pointed out its problems existing in the design of, encourage students themselves to find solution to find information. In addition, social investigation in the design courses, is also a important way to cultivate students' ability to research and analysis. 
According to the selected topic, organizes the student to give you into urban social investigation, on the basis of further research, understand the landscape and architecture, landscape and city, the relationship between landscape and environment, to cultivate students found the problem, the ability to analyze and solve problems.

Group teaching mode fully draw lessons from the western Workshop teaching concept and China's national conditions, has a certain sophistication. First of all, teaching schedule, teachers and students all work around a big table, lecture, two more than the teacher (one speaker, the other a supplement), period, students can interrupt to ask questions. Second, on teachers with large classes taught by two professional teachers, usually tutorial often employ all kinds of experts and consultants, on the periphery of the professional related knowledge and practical guidance. Third, tutorial time is flexible, usually prescribed time in class, teachers, other time when students have problems can be half a day in advance booking a teacher focus on answering questions, or answer, respectively, in the opening of the website for this grade. Fourthly, by undergraduate and postgraduate students, graduate student degree of professional often different professional (including planning, forestry, agriculture, etc.), communication atmosphere is very thick, with a strong professional knowledge and work skills complementary. Fifthly, teaching team of students Group, moderate scale, usually around $12 \sim 15$ people, the classroom is kind, especially to ensure the appropriate presentation time, each has certain fairness. The six, and strive to do with students as the center. By the students and thinking way, this problem is favourable to guide teachers, not only the teacher speak their ideal scenario, limits the students try to use your own ideas to solve perplexity problems of its own.

Design Skills. Design expression ability mainly includes the hand-painted performance ability, ability to computer aided performance, model making, performance skills and language ability. With good communication skills, design thinking to intuitively physical and chemical performance, so as to be understanding and interpretation. Good communication skills, in turn, can also help inspire, train the ability of design thinking. Ring arts students already has the characteristics of high artistic accomplishment, model ability, the design expression occupies a certain advantage, but should avoid engineering drawing is not rigorous, practicality is not strong. Language power of expression will be simulated to design report and organize groups to discuss ways to develop.

\section{A Cognitive Concept, Landscape and Structure}

The Cognition about Landscape. Channel a lot of landscape experience, often vary from person to person. Scenery is objective, can through the visual perception, so the landscape cognition have rules to follow, and also can be cultivated. Based on urban planning of architecture professional background in senior specialized direction selection landscape students teaching experiment, further confirms our landscape based teaching system of advanced specialization, that is, master the regular pattern of landscape cognition is the importance of landscape planning and design basis.

Landscape cognition is with landscape quality of space and its internal elements associated with the overall feeling and understanding. Horizon in the space of material interface is tangible, its internal components between the implication of inner and outer space. [5] A certain elements of landscape quality and the surrounding environment and other factors of the difference between the printed liner relationship: individual factors protrudes from the background "stand out" and "stand out", such as "evergreen among some red" natural combination; "Bring out the best in each other" formed between two elements "should be" to each other, such as "new moon" in Chinese traditional garden space mapping out the foreground and the background, the relationship between as well as the mountain waterfalls "container" and "water" relationship in; The winding path leading to a 
secluded spot but also reflects the touring experience for a variety of elements of the four-dimensional space-time relationship. The above examples are focusing on the landscape cognition of form and content, while the "want" to "situation in harmony" requires to fully display the inner quality of all kinds of natural scenery.

People is the main part of the cognitive object, the object is the object of cognition, and cognition is the main body of the object of landscape and aesthetic appreciation sublimation process step by step. Therefore, on the basis of people's cognitive laws, and gradually understand the natural scenery external materialized form, color, the internal mechanism of various shape color scene performance, inclusive landscape space, such as the situation in become our landscape specialization first teaching module space design.

Landscape Cognitive Space Design of the Training Set. The cognition to the landscape, not only to understand the relevance of landscape elements and the environment, more important is to grasp the main body of the viewer cognitive object in the scene of the five stages of understanding between the spiral progressive relationship: the content and form, the form and scene, view and affection, affection and condition, condition and meaning referred to in the relationship with the signifier. As the first module of landscape specialization, namely pay attention to the six landscape cognition, the space design training, and, in the aggregate, these training has five aspects: basic requirements:

(1) the understanding of the outdoor space and design;

(2) the design procedures and methods;

(3) the concept meaning of space;

(4) to express the meaning of space;

(5) the space character, artistic features, construction elements and the integrated use of natural elements.

\section{Pay Attention to the Main Content of the Training of Cognitive Space Design Landscape}

Six space design and training based on the progressive relationship of landscape cognition can be divided into two parts: the basic cognitive and advanced cognition. Basic cognition for the first part, is composed of four design training:

The Space Function and Landscape Elements-Site. Content: to observe the base, looking for an interesting place, create a site.

Requirement: the boundary of the clear outer space, function, line, use of landscape elements of space design and renovation.

The Line of Sight (Base) with the Environment-Slightly. Content: to observe the base, choose any a good visual image, design a lookout points and its environment, requirements and site characteristics and spiritual harmony, and to design a (group) in the observation that exhibition board, show the viewer interpretation.

Requirement: the observation clearly lookout around the environmental characteristics of the earth. At the lookout points to draw a picture can express what you see pictures, the main expression characteristics of the earth landscape; Analysis (perspective and profile) point of view the relationship with the land, and to observe the lookout points from other location; Understanding of the relationship between the design object and the base environment and landscape characteristics.

Roads and Landscape Display-Road. Content: select two points, and connect the way they use, to show the features of the landscape; Design a let a person feel comfortable and have road landscape quality and environmental quality. 
Requirements: master road of design factors, the nature of the road and the relationship between human behavior and psychological factors.

A Symbol of the Space and Memory. Content: the city space is symbolic of a place, commented on and memorable.

Requirements: (1) the place history cognition; (2) different landscape elements to constitute the role of space environment; (3) analysis of the status quo of spatial scale, streamline, social and cultural characteristics and the formation of the public behavior; (4) is the quality of the city symbolic or monumental space; (5) Suggestions and ideas. Advanced cognition for the second part, made up of two design training.

State Space. Content: the place with time holy value perception characteristics and spatial analysis and protection, put forward questions and conceptual design.

Requirements: (1) understanding human scale, and because of the relationship between the scale of place and soul; (2) to understand the transition boundary limit, and the meaning of "threshold"; (3) the significance of internal and external; (4) from the basic concept, nature and art to explore the relationship between the human culture and landscape; (5) explore the concept of small and large.

The Comprehensive Design-the Style of the Space and Local Design. Content: the investigation and analysis of a kind of typical historical style garden with the style of the conceptual design.

Requirements: content and methods of the integrated use of knowledge, the basic shape features and spatial form, on the basis of understanding the creation of the style is for the continuation of history and culture in the contemporary characteristics and the interpretation and presentation of local environment.

\section{The Group Try and Discusses the Way of Teaching}

The Group Teaching Compared with Traditional Teaching Methods. Group teaching mode fully draw lessons from the western Workshop teaching concept and China's national conditions, has a certain sophistication. First of all, teaching schedule, teachers and students all work around a big table, lecture, two more than the teacher (one speaker, the other a supplement), period, students can interrupt to ask questions. Second, on teachers with large classes taught by two professional teachers, usually tutorial often employ all kinds of experts and consultants, on the periphery of the professional related knowledge and practical guidance. Third, tutorial time is flexible, usually prescribed time in class, teachers, other time when students have problems can be half a day in advance booking a teacher focus on answering questions, or answer, respectively, in the opening of the website for this grade. Fourthly, by undergraduate and postgraduate students, graduate student degree of professional often different professional (including planning, forestry, agriculture, etc.), communication atmosphere is very thick, with a strong professional knowledge and work skills complementary. Fifthly, teaching team of students Group, moderate scale, usually around $12 \sim 15$ people, the classroom is kind, especially to ensure the appropriate presentation time, each has certain fairness. The six, and strive to do with students as the center. By the students and thinking way, this problem is favourable to guide teachers, not only the teacher speak their ideal scenario, limits the students try to use your own ideas to solve perplexity problems of its own. This also is teaching in our efforts to respect students' cognitive structure can try.

The Meaning of Group Teaching. Group teaching for more than three years, whether inside or outside class, stimulate the initiative of the enthusiasm of students to ask questions and communicate with each other, crossover study of complementarity and have the courage to explore innovative, but also improve the enthusiasm of the teachers, the teachers and students information 
feedback timeliness and the efficiency of teaching. Of course, the teaching way in the real perfect still have to pay quite a lot of effort to.

The Development of Group Teaching. Group teaching in the buckle landscape cognition rule, more closely in collaboration, the courses of parallel communication across professional teachers, teachers and students resources optimization combination, etc., there are still some shortage, is yet to be further improved. In addition, as the landscape more and more students after the recognition of specialization, enrollment expansion pressure is more and more outstanding, but we believe that the current for a period of time, the Group, the number of students in teaching, unfavorable and overmuch, ceiling can't break through 15 people, otherwise the interactive efficiency decreases, but cannot guarantee that every student can get opportunity to ask and answer directly classroom equal.

All in all, pay attention to the space design of landscape of cognitive training of core idea, namely the efforts in the students' cognitive regularity and landscape cognition of progressive relationship, try to build a "bridge" -- - know training level rising space. In actual spatial experience and operation practice, students to gradually improve the landscape aesthetic and appreciation ability, and finally to make masterpieces.

\section{References}

[1] Zhang Licui. Research on the teaching reform of interior design in Higher Vocational colleges. Curriculum education research. 2012 (2): 1-3

[2] Zhang Jing. On the reform of teaching mode of interior art design in Higher Vocational colleges. Journal of science and Technology 2010 (10)

[3] Zhang Qi-man, Pan Wuhua. Interior design data set 2 [M]. Beijing: China Building Industry Press. 1999

[4] Hong Yi-Min. Reform the teaching method [J] training innovative talents. Beijing: Chinese Journal of Women's College. 2008 (4)

[5] Pan Wu-hua. Indoor display art design. Beijing, China Building Industry Press, 1999 